\title{
Geotechnical optimisation of Southern Ridge Cutback 3 at Tom Price mining operations
}

\author{
TM Johnson Rio Tinto Iron Ore, Australia \\ V Pere Rio Tinto Kennecott, USA (previously at Rio Tinto Iron Ore, Australia) \\ R Dixon Rio Tinto Iron Ore, Australia \\ P de Graaf The De Beers Group of Companies, South Africa (previously at Rio Tinto Iron Ore, Australia) \\ DR Wines Itasca Australia Pty Ltd, Australia \\ Y Hebert Itasca Australia Pty Ltd, Australia
}

\begin{abstract}
The Southern Ridge Cutback 3 (STR3) at the Tom Price mine site will be the highest and steepest slope in Rio Tinto Iron Ore's Pilbara operation. Initial geotechnical assessment of the STR3 western slope using two-dimensional limit equilibrium methods recommended a substantial flattening of the design. This would have resulted in the deferral of 3.2 Mt of high grade ore. Given the good performance of the preceding STR2 cutback, it was considered that the two-dimensional (2D) analysis results were not representative of the expected stability and were overly conservative. Structures constraining the dominant mode of instability strike oblique to the slope. This aspect and the effects of 3D lateral confinement are not considered by $2 D$ analysis. In order to address this, a 3D modelling project was initiated with development of a 3D model by Itasca Australia Pty Ltd.
\end{abstract}

The 3D model method utilises both 3DEC TM (Itasca 2013a) and FLAC3D ${ }^{\text {TM }}$ (Itasca 2012) software to develop a constitutive model that takes into account the dominant bedding anisotropy within the slope. As this was the first such model developed for Rio Tinto Iron Ore (RTIO), an external review board was appointed to provide technical guidance during the project. Sensitivities were carried out to address questions regarding in situ stress regime, pervasive joint orientations relative to bedding, potential for large scale wedges, and ore friability.

Three-dimensional modelling results were favourable and indicated that the existing design exceeded stability acceptance criteria. In addition, further optimisation of the slope was possible and would realise an additional $1 \mathrm{Mt}$ of high grade recovery. In order to achieve this, revision of the slope design configuration was required. Work supporting this included assessment of the viability of 90 degree batter face angles and a re-routed haulage design. Batter-berm configurations and placement of wide geotechnical berms were tested for inherent stability and rockfall risk management effectiveness.

Overall stability of the revised slope design was confirmed by the Itasca modelling. Some areas of potential local instability were identified and have been addressed by detailed design changes.

This project demonstrates the potential value add that can be realised by 3D analysis, when compared with traditional 2D methods. Due to the high value of the STR3 ore as a blending material, this slope is being mined at a relatively high strip-ratio when compared with other RTIO Pilbara pits. This emphasises the potential impact of the protect plan and optimisation outcomes.

\section{Introduction}

Rio Tinto Iron Ore's (RTIO) mining operations span 1,000 km across the Pilbara Region of Western Australia and include 14 sites with well over 100 open pits. A long mining history, commencing in the 1960s, has 
allowed slope designs to be verified by slope performance meeting business expectations. RTIO has carried out benchmarking to demonstrate the occurrence of instability is considerably less than industry accepted Probability of Failure criteria (e.g. as documented in Table 1.1 in Stacey (2009)). The Southern Ridge Cutback 3 (STR3) is part of the Greater Tom Price mining operations (TPMO) located near Tom Price Town (Figure 1). At $350 \mathrm{~m}$, STR3 will be the highest slope in RTIO's Pilbara portfolio. In addition to this, the cutback provides a significant contribution to the premium ore supply for TPMO.

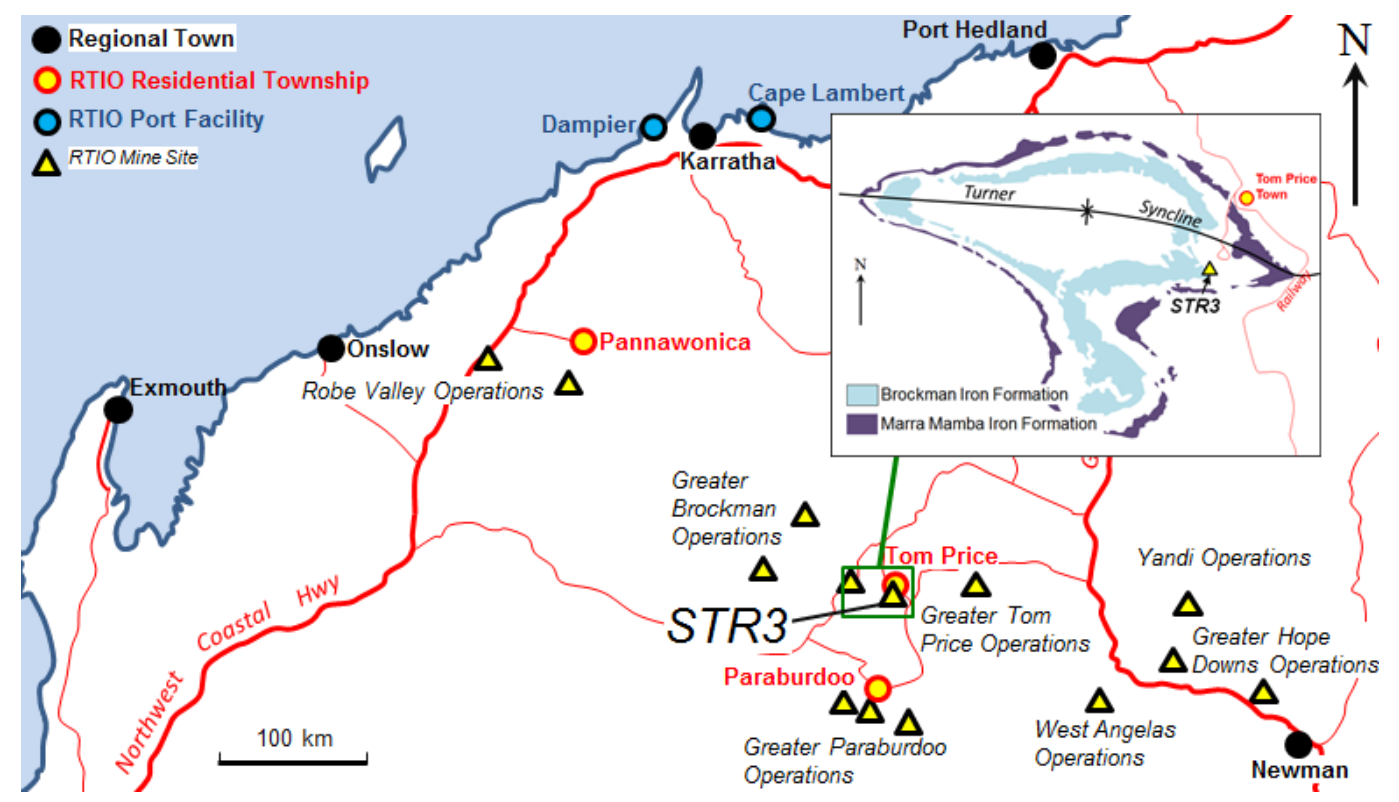

Figure 1 Rio Tinto Iron Ore's Pilbara Operations with Southern Ridge Cutback 3 location highlighted and regional geological setting shown (inset)

Pilbara geotechnical slope designs have typically been analysed using two-dimensional (2D) limit equilibrium methods with material parameters calibrated against observed slope performance. This has been facilitated by along strike mining practices with large continuous pit wall strike lengths, which have lent themselves to 2D analysis methods. In contrast, the STR3 presents a cross-strike face with the primary structural fabric dipping at moderate angles sub-parallel to the strike of the slope. Given the bedding dip direction is outside the planar sliding envelope, 2D analysis methods that model the apparent dip of bedding can result in conservative outcomes. Previous geotechnical evaluation based on 2D methods recommended flattening the overall slope angle putting a significant portion of the cutback ore recovery at risk. Successful mining of the preceding STR2 cut and the limitations of 2D analysis prompted RTIO to undertake a project to model the slope in 3D space.

A 3D model can better represent the true slope geometry, distribution of rock mass domains and orientation of geological structures and fabric. All of these factors can be important when assessing slope stability (Wines 2015). Itasca Pty Ltd was selected to develop a 3D numerical model of the slope. This was the first application of this method at a RTIO operation. The project was also supported by an external review board to provide independent oversight.

\section{Approach}

Development of a 3D numerical model to characterise the slope needed to take into account the local geology and in particular the anisotropic nature of the rock mass. The banded iron formation (BIF) and shale rock types demonstrate a significant strength anisotropy defined by the ubiquitous primary bedding. Two-dimensional limit equilibrium methods have taken this into account by incorporating both rock mass and defect shear strengths into the conceptual rock mass model. Applied anisotropic strength typically utilises gradational transition from rock mass strength to defect shear strength. This concept is integral to the linear anisotropic and anisotropic strength models incorporated into 2D limit equilibrium software such 
as Slide ${ }^{\mathrm{TM}}$ (Rocscience 2010) and is supported conceptually by laboratory testing results (an example is reported in Tien et al. 2006). This method has also been validated though it's successful application to many slopes across the Pilbara.

RTIO considered that an analogous method in 3D modelling space was needed to respect the anisotropy. This is addressed by the Itasca ${ }^{\mathrm{TM}}$ modelling approach for this project and previously outlined in Sainsbury (2013). Ahead of numerical modelling, a programme of supplementary structural data capture including drilling and mapping was carried out. This allowed refinement of the slope scale structural geological model, improvement of understanding of rock mass properties and characterisation of the structural fabric of each rock mass domain. Finally, the 3D numerical model was calibrated to existing slope performance from prism monitoring data.

Favourable model results from analysis of the base case design led to consideration of optimisation opportunities that were subsequently incorporated into the analysis programme. As the project progressed, additional parametric sensitivities and supplementary analysis were undertaken to address questions raised by the review board and to further support detailed design work. These are presented following the section of the paper that describes the 3D modelling work.

\section{Geology}

\subsection{Geological setting}

TPMO is located within the Palaeo-proterozoic to Archaean age Hamersley Basin that overlies the southern margin of the Pilbara Craton. The basin has been subjected to several episodes of tectonism forming an east-west oriented fold belt, as described in Tyler (1991) and Dalstra (2014). TMPO straddles the eastern end of the regional scale Turner Syncline as shown in the inset in Figure 1.

The STR3 deposit is hosted by the Hamersley Group of rocks. This is a sequence of BIF, shales and dolerite sills as described in Trendall and Blockley (1970) and Tyler (1991). The iron ore mineralisation at STR3 is of the Proterozoic age microplaty variety, as described in Morris (2002) and Bitencourt et al. (2002).

A feature of Hamersley group BIF is the laterally extensive persistence of bedding laminations as illustrated in Figure 2. There is little variance in internal Hamersley group lithostratigraphy or intra-BIF subdivision across the Pilbara, as described in Trendall and Blockley (1970). The implication of this is that bedding is in effect infinitely persistent at mine scales and must be considered in any stability analysis. The main mineralised unit at STR3 is the Dales Gorge Member of the Brockman Iron Formation. The Dales Gorge Member features a number of discrete shale bands that persist across the Pilbara.

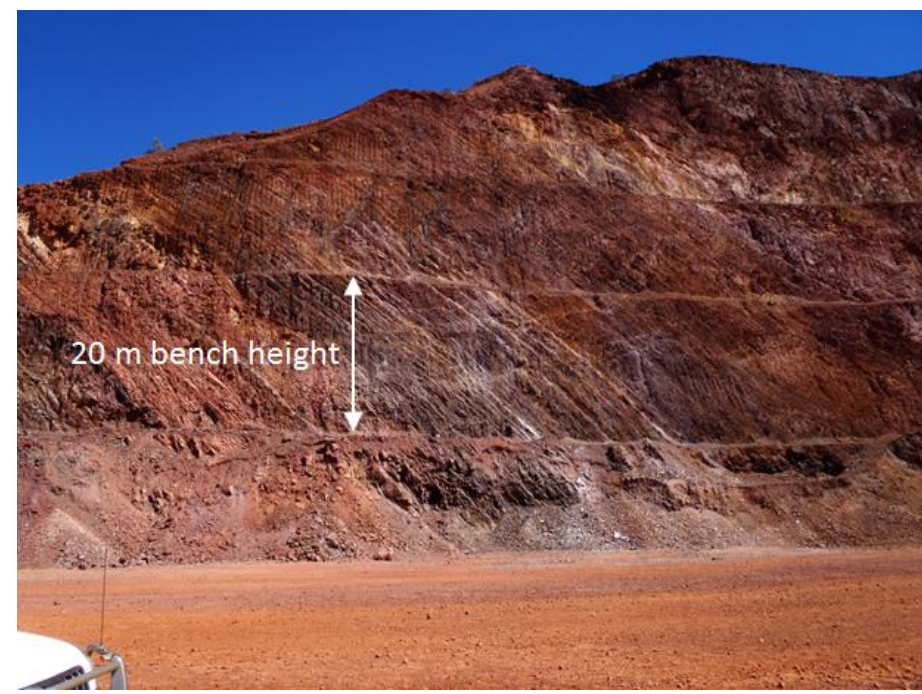

Figure 2 Example of bedding anisotropy from STR3 - Whaleback Shale and Joffre Member. Note white shale bands 
The STR3 rock mass has been subject to surficial weathering processes resulting in oxidisation of black shale and development of a surface hardcap. Alteration of BIF to ore can result in highly variable rock strength as documented in Morris (2002) and Taylor et al. (2001). The variable physical properties of ore needed to be addressed specifically during the course of the project and is discussed in Section 8.4.

\subsection{STR3 structural geology}

As shown in Figure 3, the STR3 slope features a number of discrete rock mass domains defined by both conformable lithological units and cross cutting dolerite dykes, faults and jointing. Discrete 1-3 m wide shale bands can be distinguished in the Dales Gorge Member and are defined discretely in RTIO structural models. Shale units up to $50 \mathrm{~m}$ thick such as the Whaleback Shale and Mt McRae Shale are also present within the STR3 slope. These are assigned ubiquitous shale defect shear strengths given the internal BIF and shale banding is too closely interlaminated to separately distinguish in the model.

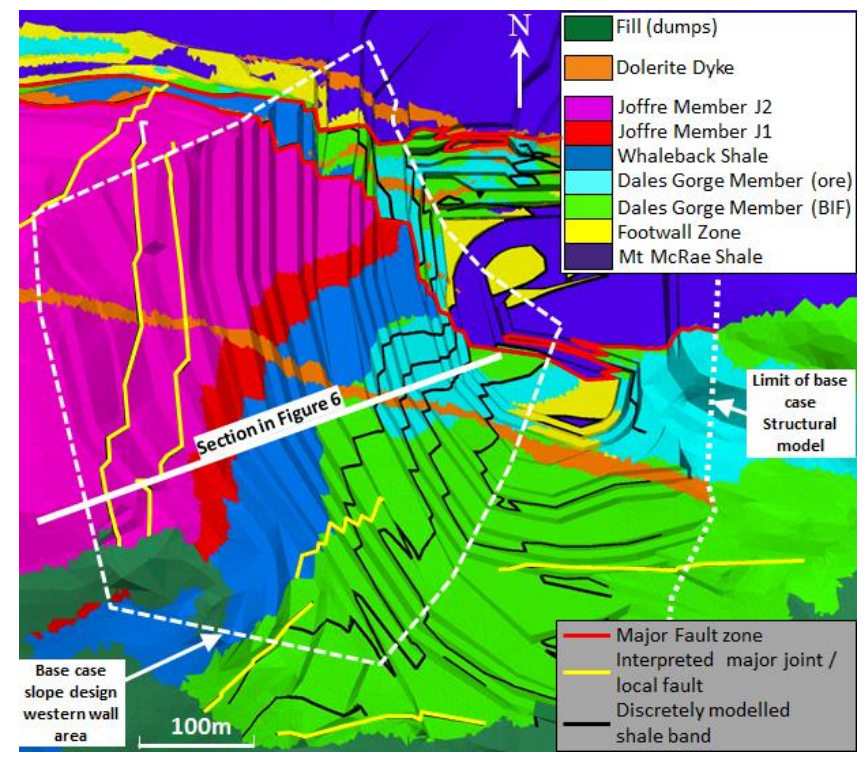

Figure 3 Plan of the STR3 base case design showing geological relationships (adapted from FLAC3D model graphic)

Bedding dips at moderate angles to the north. In effect, the dip direction is sub-parallel to the strike of the STR3 western slope. Two-dimensional cross-sections can show a shallow apparent dip out of the slope to the northeast given the dip direction and slope orientation are not exactly perpendicular in some slope sectors. Joints are well developed as shown in Figure 4, but typically exhibit limited persistence at less than bench height. Initial mapping of the slope resulted in the delineation of some large scale persistent joints described as mega-joints.

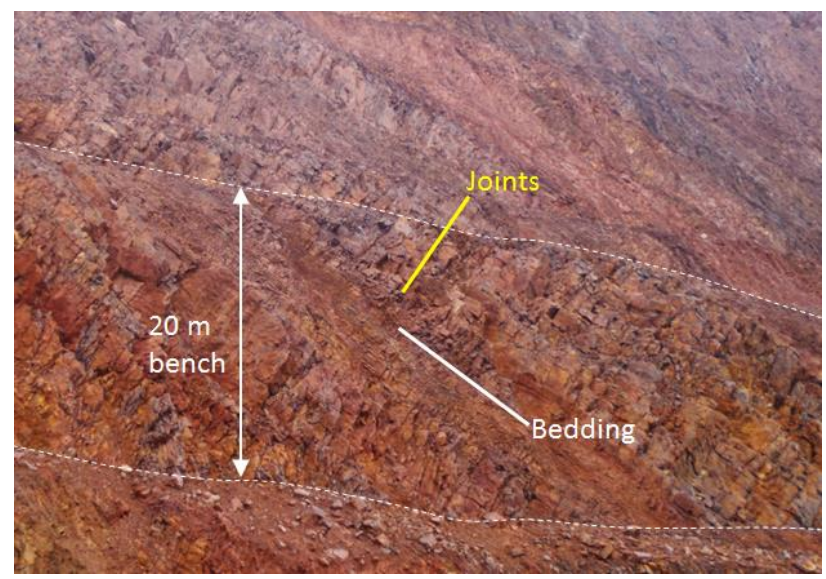

Figure 4 Photograph of STR3 batter faces showing bedding and jointing 
These larger joint structures represent a worse case interpretation generated by structural geologists by linking individual occurrences of joints in similar orientations to infer continuous surfaces. Evidence that they are interlinked without significant rock bridging is limited with no large scale continuous structures observed on cut slope faces. Nonetheless, discrete representations have been included in the geotechnical model. An example of an east-west cross-section illustrating the inter-relationship between the mega joints, bedding and the slope design is presented in Figure 5.

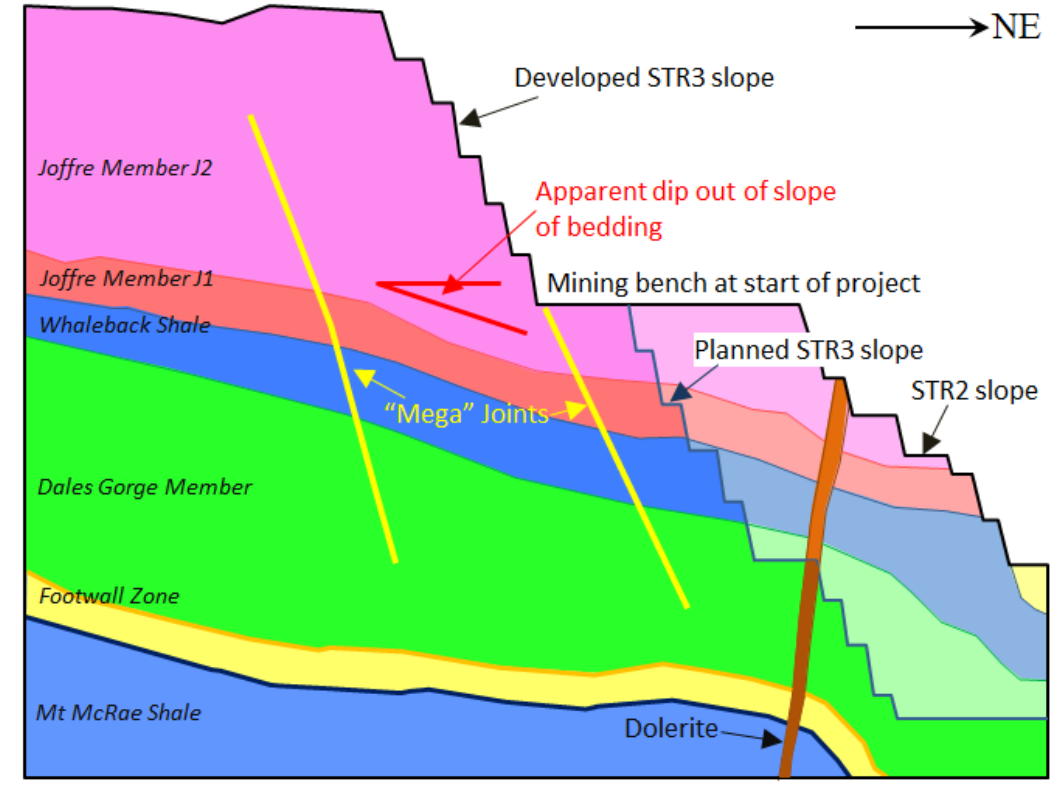

Figure 5 Cross-section through the STR3 slope (east facing wall) illustrating structural/stratigraphic relationships (bench height is $20 \mathrm{~m}$ )

\section{$4 \quad$ Field investigation}

A drilling program was undertaken in the STR3 area prior to updating the 3D models. The focus was on improving the structural model and refining understanding of both joint condition and properties. Confirming the presence and extent of the mega-joints was a key focus of the drilling programme design.

A total of 13 holes including 1,440 m of Reverse Circulation (RC) Drilling Record and 1,115 m of diamond core were planned for the drill programme and included a full suite of geophysics that included natural and induced gamma, acoustic and optical televiewer, caliper and gyro. Laboratory samples were taken during the drill programme and included sampling for shear strength on natural joints and bedding, unconfined compressive strength (UCS), Hoek cell triaxial tests, and Brazilian Indirect Tensile strength tests. Field point load tests were also carried out during logging.

An intensive field mapping campaign was also undertaken to compliment the drilling and to add further detail to the structural modelling. This included scanline and cell (window) mapping on multiple benches on both the east facing STR2/3 face and on the north facing STRW (Southern Ridge West) face (to minimise the effects of orientation bias). Detail captured in the mapping included rock material and joint characterisation, structural orientations, and geological strength index (GSI) estimates using the charts presented in Marinos and Hoek (2001) as applied to $20 \mathrm{~m}$ height batter faces.

A revised 3D structural model was constructed in Vulcan ${ }^{\mathrm{TM}}$ Software using the new drilling and mapping data.

\section{$5 \quad$ Rock mass model}

Identification of the key geotechnical domains is required in order to define the model rock mass parameters. Secondly, all available data sources were to be interrogated to identify the inputs required to calculate the parameters for the Hoek-Brown and Mohr-Coulomb strengths envelopes. 
The Hamersley Group stratigraphic sequence exposed in the STR2 wall and used in the existing STR3 designs were the basis for the initial domains, typically referred to as 'strat or strand'. A stratigraphic column of the Brockman Iron Formation and underlying units is presented in Figure 6 . These domains were then further subdivided where significant variance in the rock properties could be identified; typically further division occurred at existing lithological boundaries, referred to as strand, and also where mineralisation occurred, due to the potential strength reduction. The other key division was for a dolerite dyke that dips at a steep angle sub-parallel to the STR3 face. A total of eight domains were defined for use in the FLAC3D ${ }^{\text {TM }}$ model and are listed in Table 1.

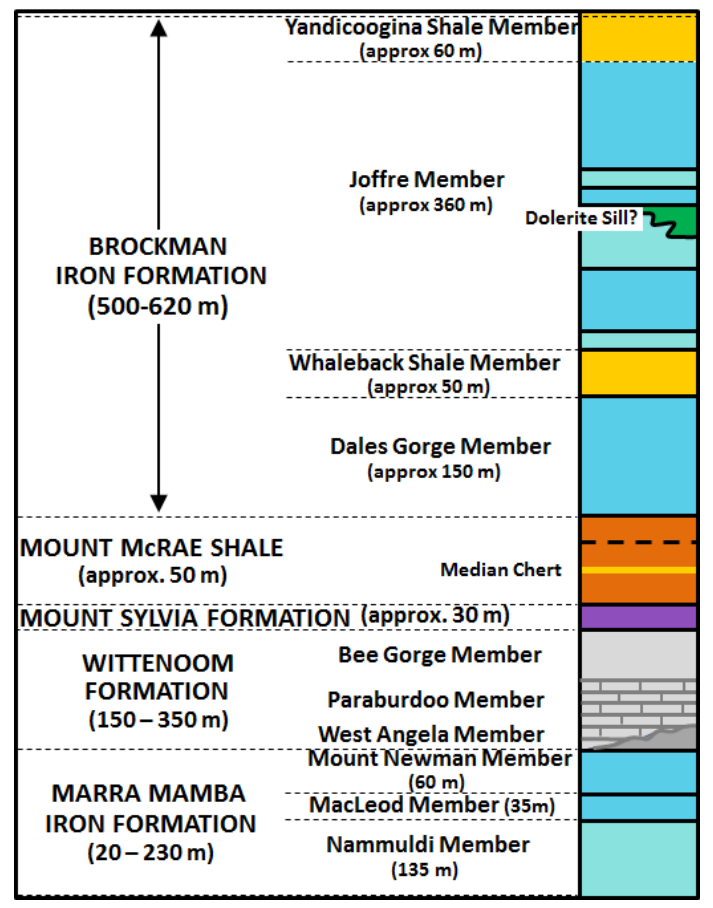

Figure 6 Stratigraphic column (after RTIO 2010)

Table 1 Geotechnical domains used in the FLAC3D ${ }^{\mathrm{TM}}$ models

\begin{tabular}{cc}
\hline Units & Description \\
\hline J2 & Joffre J2 strand \\
\hline J1 & Joffre J1 strand \\
\hline WS & Whaleback Shale (undifferentiated) \\
\hline DG UNMIN & Dales Gorge - unmineralised \\
\hline DG MIN & Dales Gorge - mineralised \\
\hline FWZ & Footwall zone \\
\hline MCSU & Mt McRae Shale - upper \\
\hline DOR & Dolerite \\
\hline
\end{tabular}

Each of the identified geotechnical domains had a factual summary report developed for it. The factual summary captured all known information including:

- Unit weight.

- Laboratory data.

- Point load tests. 
- Field estimated strength.

- Previously reported values.

- GSI.

- Mohr-Coulomb strength values for rock mass and discontinuities.

- Discontinuity spacing, persistence and condition.

- $\mathrm{mi}$.

- Representative photos of core and outcrop.

- Shear strength allocation (breakdown of shale versus BIF defect percentage in each unit and allocation of respective defect shear strength).

An allocation of defect (bedding) shear strength was made for each domain and was based on the percentage of shale beds to BIF beds within the respective domain. The quantitative GSI chart proposed by Cai et al. (2007), was used to calculate the average block volume for each modelled domain.

Based on the joint fabric information provided by RTIO and the estimated block volume, 3DEC ${ }^{\mathrm{TM}}$ (Itasca 2013a), conceptual rock mass models were generated for each rock mass unit as discussed in the section on discontinuum triaxial modelling.

\section{$6 \quad$ Modes of instability}

Given the obliquity of bedding to the slope aspect and the limited joint persistence, a rock mass or step-path mode of instability was expected to be the most likely failure mode reported by the 3D model. Historic 2D analysis reported stability concerns based on planar sliding mechanisms associated with modelling apparent rather than true bedding dips and can be regarded as kinematically invalid. Past 2D analysis also does not take into account the lateral break-out required to develop instability.

\section{$7 \quad 3 D$ modelling method}

\subsection{Overview}

Typical slope stability analyses using 3D methods often assume either isotropic rock mass conditions, i.e. the rock mass strength is the same in all directions, or are limited in methods that can be used to apply anisotropy to the model. The challenge in the Pilbara is that a model of the anisotropic nature of the rock units must be referenced directly to the 3D geometry of the primary bedding. The folded bedding envelope must be reflected in the 3D model with strength anisotropy represented accordingly. Itasca has developed a technique to simulate the behaviour of anisotropic rock masses in a slope-scale numerical model, as discussed in subsequent sections.

Initially, numerical samples for each rock mass domain are created with the three-dimensional distinct element code $3 D E C^{\mathrm{TM}}$. 3DEC ${ }^{\mathrm{TM}}$ allows explicit representation of a large number of structures, including bedding planes and joints. Slip, separation and rotation along explicit structures can occur while the individual blocks can deform and yield. The numerical 3DEC ${ }^{\mathrm{TM}}$ samples include explicit representation of the bedding and joints based on the field investigation data. These numerical samples could also be described as Synthetic Rock Mass (SRM). Numerical triaxial tests are performed on these samples to gain an understanding of the likely behaviour of each rock mass domain for different loading directions.

These numerical triaxial tests can be successfully performed on 3DEC $C^{\mathrm{TM}}$ samples at the bench-scale, however, it is not practical to construct and run a 3DEC ${ }^{\text {TM }}$ slope-scale model with explicit representation of the bedding and joints at the scale required to analyse the full STR3 slope. This would require the explicit representation of millions of structures. Therefore, the computational intensity of the resulting model 
would lead to very long run times. For this reason, when using this anisotropic analysis approach, the continuum code FLAC3D ${ }^{\mathrm{TM}}$ is used to perform the slope-scale analyses.

A calibration process is performed to ensure that the rock mass behaviour in the FLAC3D ${ }^{\mathrm{TM}}$ continuum is similar to that produced by the $3 \mathrm{DEC} \mathrm{CM}^{\mathrm{TM}}$ discontinuum samples. This is achieved by utilising the "ubiquitous joints' in FLAC3D $\mathrm{D}^{\mathrm{TM}}$, which provide an orientation of weakness in each model zone. Triaxial tests are performed in FLAC3D ${ }^{\mathrm{TM}}$, with different loading directions for each rock mass domain to ensure that a reasonable calibration is achieved. This calibrated behaviour is then represented in the slope-scale FLAC3D ${ }^{\text {TM }}$ model.

\subsection{Discontinuum triaxial models}

Synthetic anisotropic rock mass samples including explicit representation of the bedding planes, orthogonal jointing and shale bands were generated in $3 D E C^{\mathrm{TM}}$ for each geotechnical domain. The samples were constructed based on the rock mass and structure properties determined from field investigations and laboratory testing for each rock mass domain. The material in between the explicit bedding and joints is treated as intact rock. When calculating the properties for this intact material, the best-estimate UCS values were reduced by $20 \%$ to account for scale effects associated with micro-flaws (pores, open cracks, veins) and weathering/alteration. The shear strength properties assigned to the bedding and joints was estimated using the empirical Barton-Bandis criterion (Barton \& Bandis 1990).

An example 3DEC ${ }^{\mathrm{TM}}$ sample is shown in Figure 7.
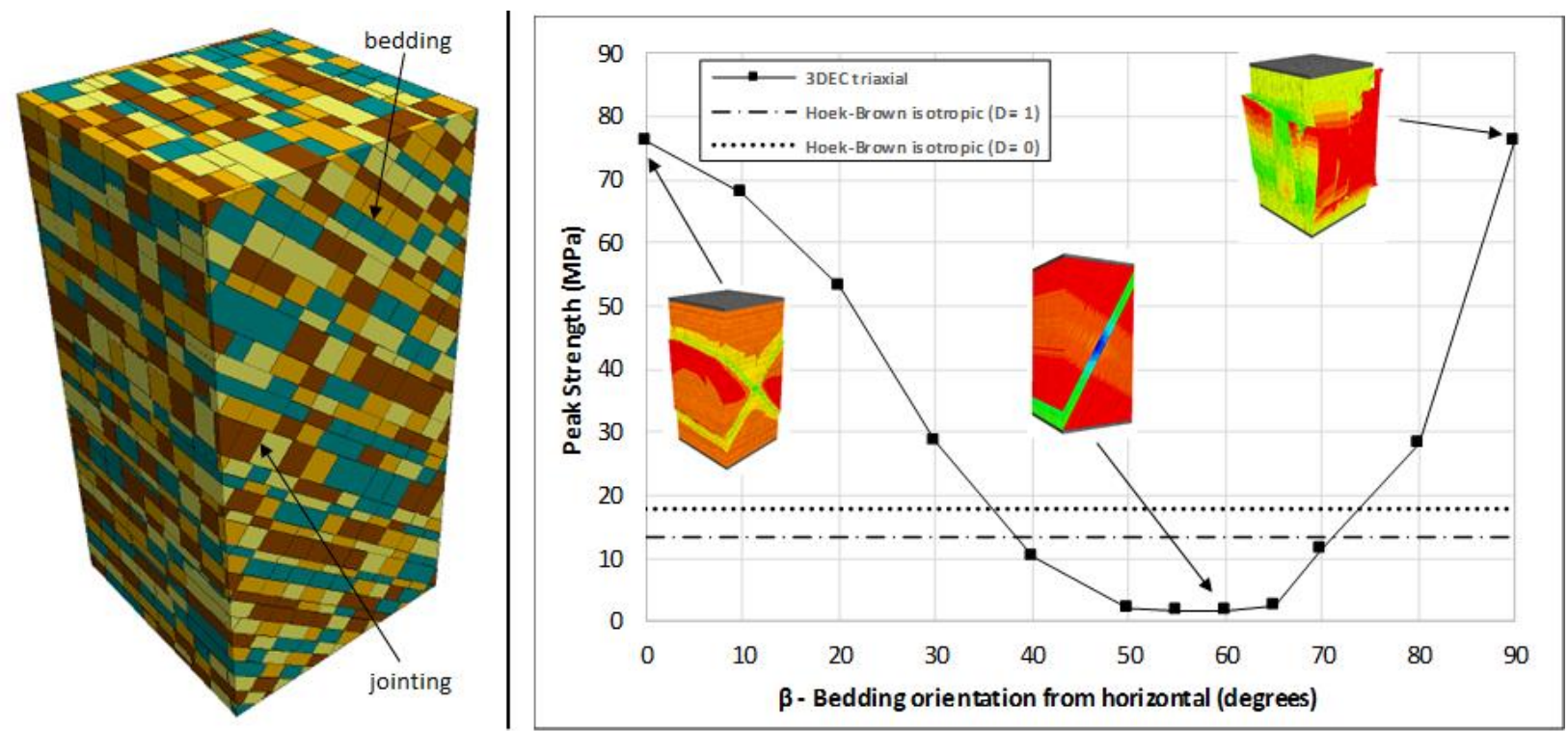

Figure 7 Example of synthetic anisotropic rock mass generated with 3DEC ${ }^{\mathrm{TM}}$ (left) and example of triaxial test results for varied bedding orientations with respect to loading direction (right)

Numerical testing was performed on the samples for varying bedding plane dip angles at a confinement equivalent to the anticipated failure model depth at overall slope scales. Strain-softening is applied to both the intact rock and the discontinuities, whereby the strength can reduce based on plastic shear strain. An example of the test results is provided in Figure 7, showing the resulting U-shaped strength curve. Note that $\beta$ is the angle between the bedding and a horizontal plane, and the shale bands always follow the bedding orientation. It is seen that the strength is lowest with $\beta$ angles of between 50 and $65^{\circ}$, where shear failure can occur along the bedding planes and/or shale bands. The strength is highest when the loading direction is perpendicular to the bedding $\left(\beta=0^{\circ}\right)$ or parallel to the bedding $\left(\beta=90^{\circ}\right)$. In these cases, the intact rock strength has more influence on the sample strength, because shear failure is not able to occur along the bedding planes or shale bands. The degree of anisotropy, i.e. the ratio between the highest and 
lowest strength, is seen to be significant. This reflects the difference in strength between the intact rock and the bedding planes/shale bands.

Note that the isotropic (Hoek-Brown) strength, as estimated using the approach presented by Hoek et al. 2002, is also shown as horizontal lines in Figure 7. It is seen that the isotropic strength falls in between the highest and lowest strength produced by the anisotropic 3DEC ${ }^{\mathrm{TM}}$ testing. Example 3DEC ${ }^{\mathrm{TM}}$ models and corresponding photographs for contrasting rock mass domains are shown in Figure 8.

\section{J2 Domain}

a) $3 D E C$ sample $\left(\beta=0^{\circ}\right)$

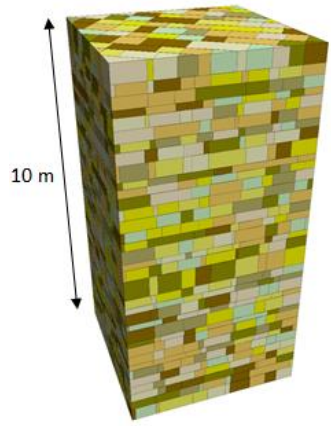

b) Photograph of J2 domain

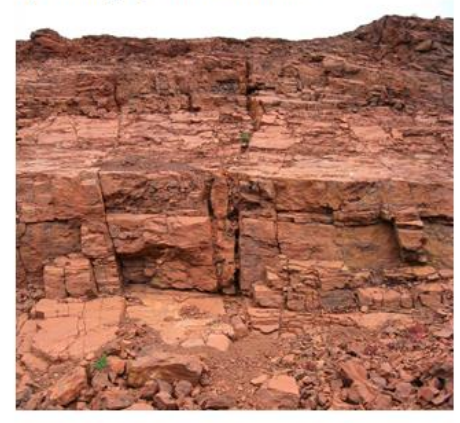

WS Domain

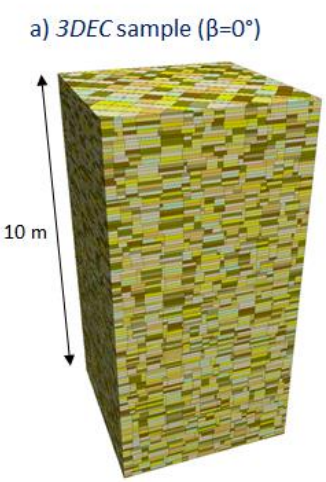

b) Photograph of WS domain

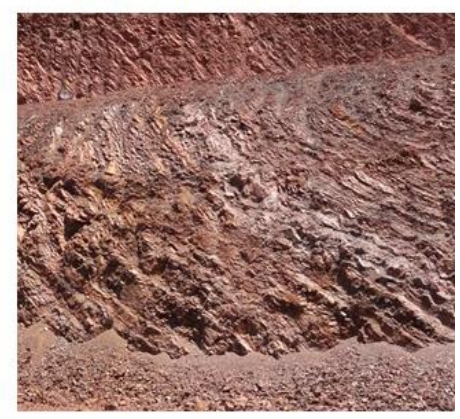

Figure $8 \quad 3 D E C^{\mathrm{TM}}$ models for Joffre Member (J2) BIF and Whaleback Shale (WS)

It is noted that, although the terminology used to describe these numerical triaxial tests is similar to that used for laboratory testing, the numerical test results are not calibrated to laboratory test results in any way. To incorporate a reasonable amount of structure in the numerical samples, and therefore provide a reasonable assessment of the anisotropic behaviour created by the spacing of bedding and jointing at real-world scales, the numerical samples are $10 \mathrm{~m}$ in height and $5 \mathrm{~m}$ in width. Laboratory testing of rock or rock masses has not been undertaken at this scale, therefore calibration to laboratory data is not possible. Due to the limited sample size, the results of typical laboratory testing, e.g. UCS and triaxial tests, will generally be more representative of the intact rock than the rock mass except for finely laminated rock types.

\subsection{Continuum triaxial models}

As discussed, the slope-scale stability analyses were performed using the continuum code FLAC3D ${ }^{\text {TM }}$. The behaviour of the FLAC3D ${ }^{\mathrm{TM}}$ continuum was calibrated to the $3 \mathrm{DEC} \mathrm{C}^{\mathrm{TM}}$ triaxial tests. This was achieved using a strain-softening, ubiquitous joint constitutive model in FLAC3D ${ }^{\mathrm{TM}}$, whereby 'ubiquitous joints' are used to represent an orientation of weakness in each model zone.

To reproduce the $3 D E C^{T M}$ explicit anisotropic response, the FLAC3D ${ }^{\mathrm{TM}}$ model needs to simulate persistent bedding, as well as non-persistent orthogonal joints. Only one ubiquitous joint orientation can be assigned to each FLAC3D ${ }^{\mathrm{TM}}$ zone. Therefore a routine was developed using the FLAC3D ${ }^{\mathrm{TM}}$ in-built programming language (FISH) to dynamically change the orientation and properties of the ubiquitous joints during the calculation process if failure occurs along one of the given directions. This allows the ubiquitous joint orientation to alternate between bedding and orthogonal joints. To simulate the non-persistent orthogonal joints, a percentage of randomly distributed ubiquitous joints was fixed to the bedding orientation and could not change to the orthogonal joint orientation.

To calibrate the FLAC3D ${ }^{\mathrm{TM}}$ model response to the $3 \mathrm{DEC} \mathrm{C}^{\mathrm{TM}}$ triaxial tests, a series of triaxial tests were simulated in FLAC3D ${ }^{\mathrm{TM}}$ with $\beta$ angles from 0 to $90^{\circ}$ for each rock mass domain. In general, the same input properties as those adopted for the $3 \mathrm{DEC}^{\mathrm{TM}}$ samples were used. The calibration of the FLAC3D ${ }^{\mathrm{TM}}$ response to fit the $3 D E C^{\mathrm{TM}}$ explicit response consisted of adjusting three parameters: (1) the percentage of orthogonal joints (ubiquitous joints assigned to the bedding direction and able to rotate to the orthogonal direction), (2) the percentage of ubiquitous joints with shale properties, and (3) the matrix UCS. An example calibration between the $3 \mathrm{DEC}^{\mathrm{TM}}$ and FLAC3D ${ }^{\mathrm{TM}}$ triaxial test results is provided in Figure 9. 


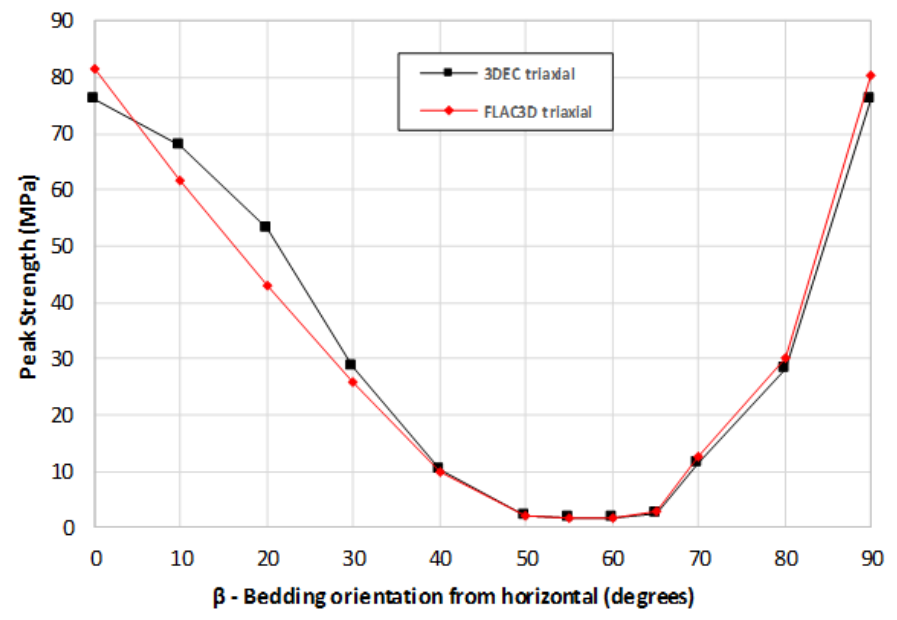

Figure 9 FLAC3D ${ }^{\mathrm{TM}}$ triaxial response compared to the explicit 3DEC simulation results

\subsection{Slope scale FLAC3D model}

To analyse the wall in 3D, a FLAC3D ${ }^{\mathrm{TM}}$ model was constructed for the entire STR3 slope using the automatic mesh generator Kubrix Geo (Itasca 2013b). A hexahedral mesh was used to provide an accurate representation of the plasticity that may occur in the rock mass adjacent to the slope. Twenty shale bands and faults were simulated as explicit interfaces within the model. Interfaces in FLAC3D ${ }^{\mathrm{TM}}$ have no thickness and are characterised by Coulomb sliding and/or tensile and shear bonding. These structures were built into the model during the initial mesh construction and accurately follow the geometry and extent of the interpreted surfaces for each structure.

The properties obtained from the calibration process detailed above were adopted for each rock mass domain. A routine was developed within FLAC3D ${ }^{\mathrm{TM}}$ to assign the orientation of the ubiquitous joints throughout a large-scale model based on any number of wireframes. Figure 10 illustrates the ubiquitous joint orientations aligned with the bedding in the FLAC3D ${ }^{\mathrm{TM}}$ model in addition to the rock mass domains.

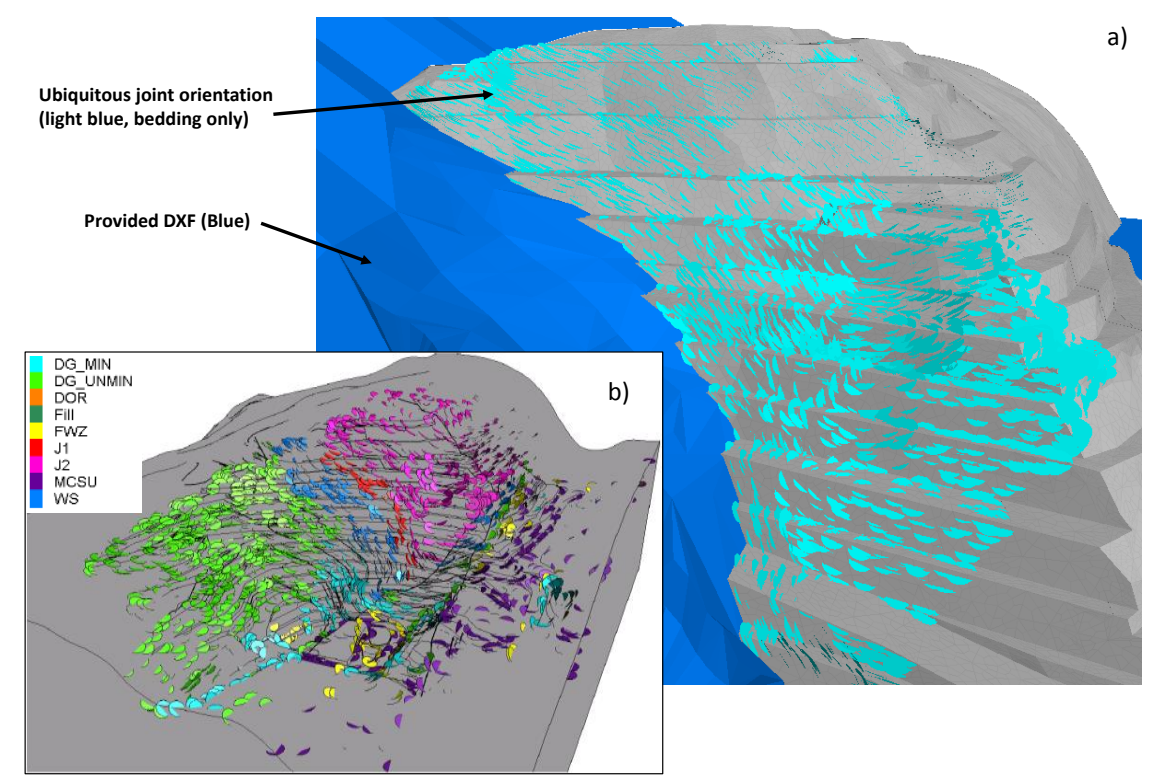

Figure 10 Ubiquitous joint orientations (bedding only): (a) compared to one surface of the bedding trace; and, (b) assigned throughout the FLAC3D ${ }^{\mathrm{TM}}$ model. For the clarity of the plot, ubiquitous joints are presented for $1 \%$ of the zones on the final pit wall

For open pit analyses, the strength properties are often degraded below peak estimates to account for various effects including stress relaxation and blasting. For the STR3 slope-scale analyses, the rock mass and 
structures are represented using strain-softening models, which allows the model to represent stress-induced damage caused by excavation of the slope. The residual shear strength adopted for the joints is equal to the estimated basic friction angle (with zero cohesion). The residual strength adopted for the intact rock is based on the properties of a broken rock (or loose rock fill) material. These assumptions are considered to be conservative.

Blast damage was represented by eliminating the cohesion from all ubiquitous joints within $20 \mathrm{~m}$ of the pit face as the assumed limit of blasting effects. This assumed depth is not based on field measurements. It is however consistent with the recommendations provided by Hoek and Karzulovic (2000), who suggest that the depth of blast damage is 1 to 1.2 times the bench height for production blasts with some control. Additional sensitivities have also been run with different assumed blast damage depths, as discussed in Section 8.5.

The phreatic surface is well below the slope, therefore pore pressures were not incorporated into the model. Excavation in the model was simulated in several stages, initially to the current pit geometry, then to the final pit design. Monitoring points were incorporated in the model at the same locations as the prisms to allow a comparison between the modelled and monitored displacements.

\section{$8 \quad$ Modelling results}

\subsection{Base case model (existing design)}

At the time the analyses were undertaken, excavation of the STR3 cutback had commenced in the upper slope, while the lower benches of the current pit had been formed by the previous STR2 cutback. The model was initially excavated to the current pit, at the time the analyses were undertaken, and the model behaviour was found to be consistent with the observed performance of the current STR2 and STR3 slopes. In particular, no multi-bench or overall slope failures occurred in the model, which was consistent with the actual slope behaviour. A comparison was also made between the modelled and monitored displacement for several prism locations, and the model was calibrated to obtain a good correlation with the monitored magnitude and evolution of the slope displacements observed in the current pit. An example comparison between the modelled and monitored displacements for one prism is provided in Figure 11.

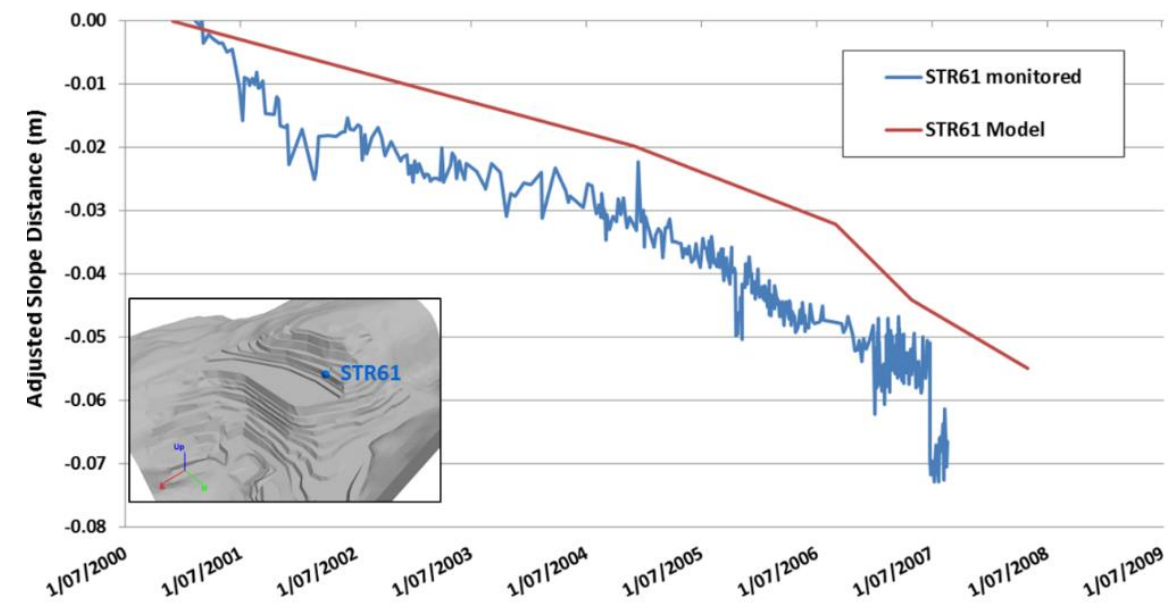

Figure 11 Comparison of prism and model displacement for Prism STR61

Various model parameters were studied to analyse the expected behaviour of the final STR3 wall, including model displacements, velocity and strains. Strength reduction analyses were also performed to predict the Factor of Safety (FS) for the slope. All strength parameters are reduced by the same factor for each strength reduction analysis, including the matrix shear and tensile strength, the ubiquitous joint strength and the strength assigned to the interfaces. The FS is represented as contours in Figure 12. The black contour indicates areas with a FS less than 1.0 (areas of instability before strength reduction, example circled), while 
areas in dark grey have a FS greater than 1.5. In terms of global stability, the modelling indicated a safety factor of at least 1.5. RTIO design acceptance criteria requires a FS $>1.2$ for overall/inter-ramp slopes (>1.3 if a long term ramp is part of the slope design (no infrastructure)).

Other localised areas had lower safety factors, and these were generally associated with potential failures along the relatively weak shale bands.

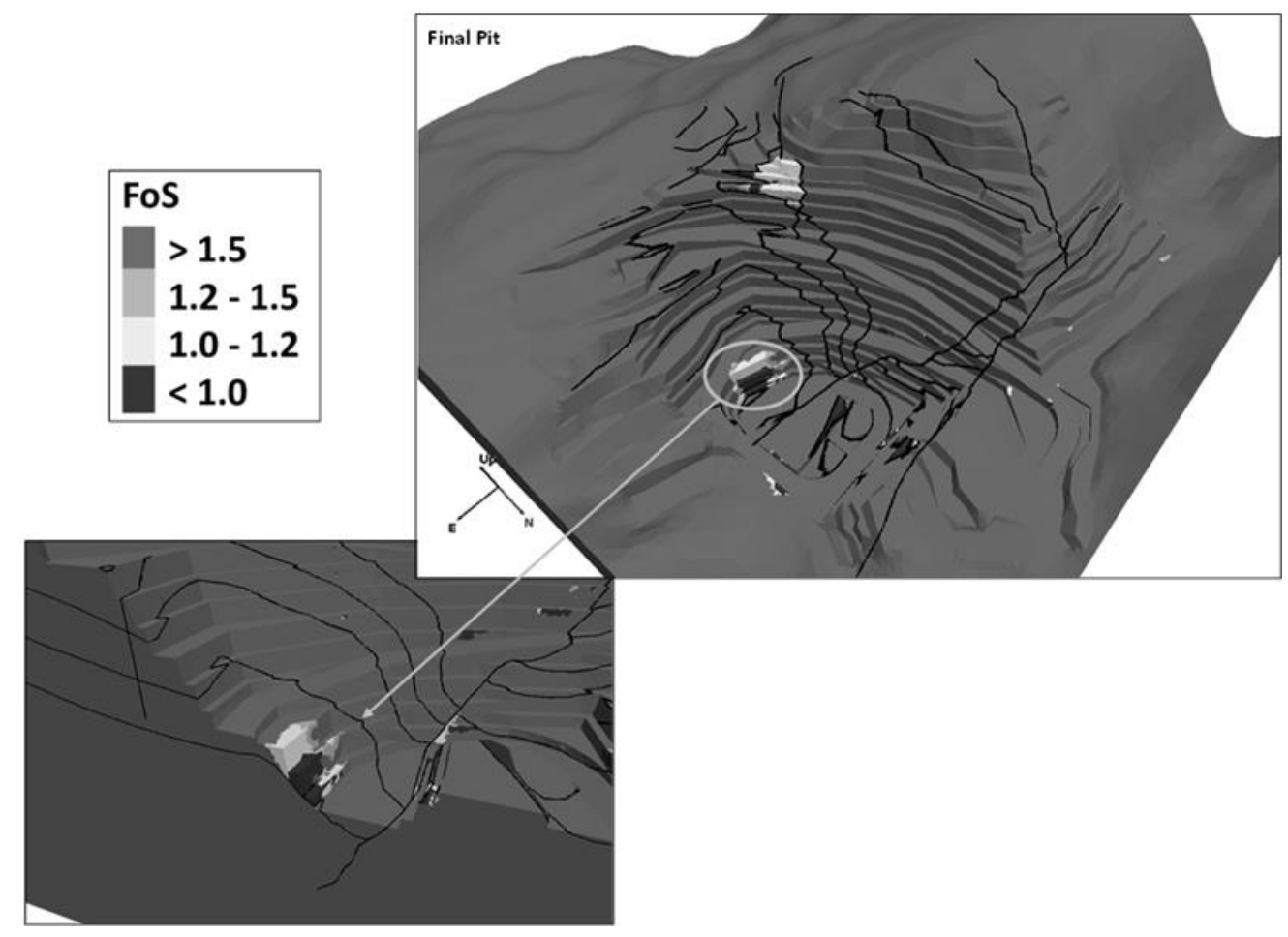

Figure 12 Factor of Safety contours for final STR3 pit wall (base case design)

\subsection{Optimised design}

Following presentation of the base case FLAC3D ${ }^{\mathrm{TM}}$ model, the following conclusions were reached:

- The existing design for STR3 was largely stable on an overall scale.

- Localised instabilities identified in FLAC3D ${ }^{\mathrm{TM}}$ could be addressed by revising the design.

- Given overall stability, steepening and hence optimising the design for increased ore recovery was possible.

In order to realise a steeper slope, a revised design configuration and strategy was devised that moved a lower haulage road to the north wall and extended the lower pit to the east. This, combined with an increase in batter face angle from 80 to $90^{\circ}$, allowed the inter-ramp angle to be increased to realise significantly improved ore recovery. The optimised design was then subject to further FLAC3D ${ }^{\text {TM }}$ modelling with the outcome shown in Figure 13. As with the preliminary result, the global slope stability FS for the optimised design was greater than 1.5. Any predicted instability is localised and confined to the lower benches. These areas were addressed by detailed changes to the design. 


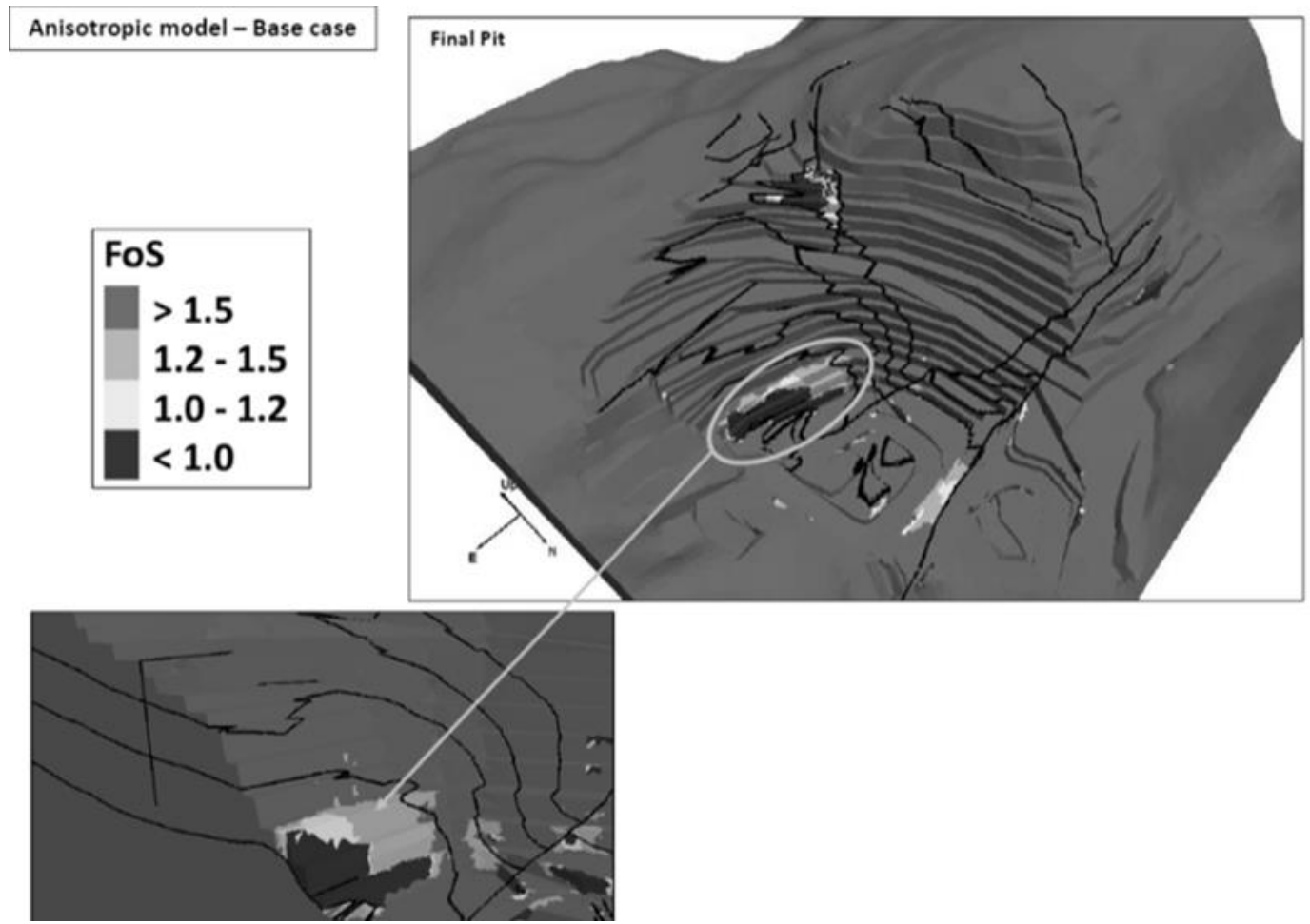

Figure 13 Factor of Safety contours for the optimised STR3 design (prior to changes to the design addressing predicted instability at the toe of the southern slope)

\subsection{South wall extended model}

Optimisation of the slope resulted in significant extension and cutback of the southern wall when compared to the base case design. During design work resolving localised issues identified by the optimised FLAC3D ${ }^{\text {TM }}$ model it was realised that the base case model extent did not encompass the full extent of the optimised design. In addition, a large scale mechanism on the south wall was identified that could result in sliding on Dales Gorge shale beds with a potential break-back of approximately $220 \mathrm{~m}$ into an overlying dump. An extended FLAC3D ${ }^{\mathrm{TM}}$ model developed, as illustrated in Figure 14. Although essentially a planar sliding mechanism, an extension of the FLAC3D ${ }^{\mathrm{TM}}$ model was considered necessary given substantial lateral rock-mass breakout is required for instability to develop.

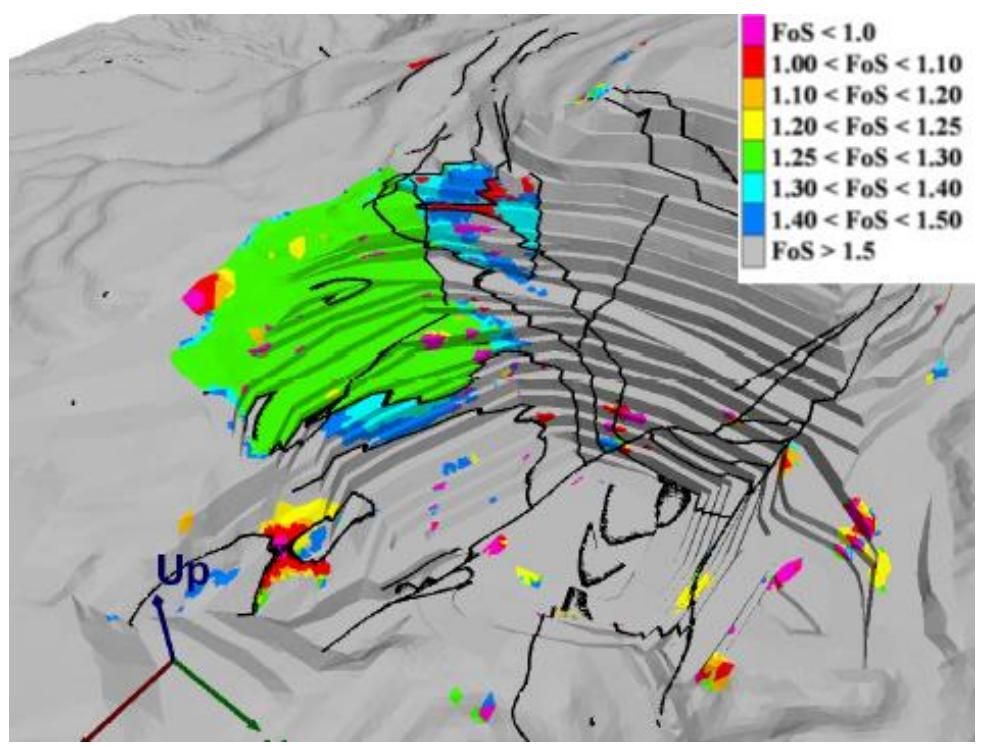

Figure 14 Factor of Safety contours for extended FLAC3D ${ }^{\text {TM }}$ model showing south wall zone at a Factor of Safety at $\sim 1.2$ 
From this analysis it can be concluded that although the slope is predicted to be stable, it is at a reduced FS compared with the western wall. Although it is noted that the predicted sliding plane (a shale band) is not day-lighted until after major haulage shifts to the north wall, the potential scale of instability warrants careful management. In particular, borehole instrumentation will be needed to provide early warning of instability.

\section{$9 \quad$ Parametric sensitivities}

A number of sensitivities were carried out in order to test model assumptions and the effect of geological variability. These are discussed below.

\subsection{In situ stress}

The base case FLAC3D ${ }^{\mathrm{TM}}$ model assumed a horizontal to vertical in situ stress ratio of 2:1. Review board feedback recommended a sensitivity run to test the influence of in situ stress on the result. No in situ stress work has been undertaken in the STR3 area. Villaescusa et al. (2012) indicates that a horizontal to vertical ratio $(\mathrm{H}: \mathrm{V})$ range between $1: 1$ and $2.5: 1$ should be representative for a depth of $370 \mathrm{~m}$, a comparable height to the STR3 final wall. The stress relief associated with lack of confinement of the STR3 ridge puts the expected in situ stress at the lower end of any possible stress range. The $\mathrm{H}: \mathrm{V}$ ratio of 2:1 was adopted on this basis as a reasonable maximum.

Stress field maps (e.g. WSMP 2013) report sparse data for the inland Pilbara, although this and measurements off the Pilbara coast suggest an east-west principal stress orientation. This would be aligned with the east-west regional structural grain of the province. A revised stress ratio of 2:1:1 is proposed ( $\mathrm{H} 1: \mathrm{H} 2: \mathrm{V}$ where $\mathrm{H}$ is horizontal and $\mathrm{V}$ is vertical) with the principal stress acting in an east-west orientation. FLAC3D ${ }^{\text {TM }}$ runs for 1:1, 2:1, and 2:1:1 horizontal to vertical stress ratios reported no significant influence on model results. As the horizontal stresses were increased, the predicted deformation magnitudes and the extent of the predicted localised failures increased slightly, however the effects were not significant.

\subsection{Orthogonal joint orientation in FLAC3D ${ }^{\mathrm{TM}}$}

Using the methodology described earlier, only one set of orthogonal joints is represented in the FLAC3D ${ }^{\text {TM }}$ model. For the base case numerical analyses detailed above, the orthogonal joints in the slope-scale FLAC3D ${ }^{\mathrm{TM}}$ model were defined with a strike of $90^{\circ}$ to bedding. This is based on mapping data. However, additional sensitivity studies were performed to assess the potential impacts of a different orthogonal joint orientation, where the bedding and orthogonal joints have the same strike. The orientation of the orthogonal ubiquitous joints in the slope-scale model was found to have an insignificant impact on the modelling results.

\subsection{Ore strength}

The mineralised Dales Gorge material is expected to be encountered in the lower benches of the final STR3 wall ('DG_MIN' domain in Figure 10). This mineralised zone includes strong, blocky material, with some weaker, friable material. A detailed geological model of ore strength was not available as a FLAC3D model input. Stacey (2013) raised weak Brazilian iron ores that have had a detrimental impact on stability as a potential analogue (see Aquino et al. 2009). This concern was addressed via the following approaches:

- Generation of a visual representation of STR3 ore hardness distribution based on geological strength logs (benchmarked against indicative UCS tests) as shown in Figure 15. The majority of the ore in the vicinity of STR3 can be classified as medium to hard with the closest equivalent to Brazilian 'powder' ores largely absent. Ore hardness classifications are from the RTIO internal ore code system documented in Bitencourt et al. (2002). 


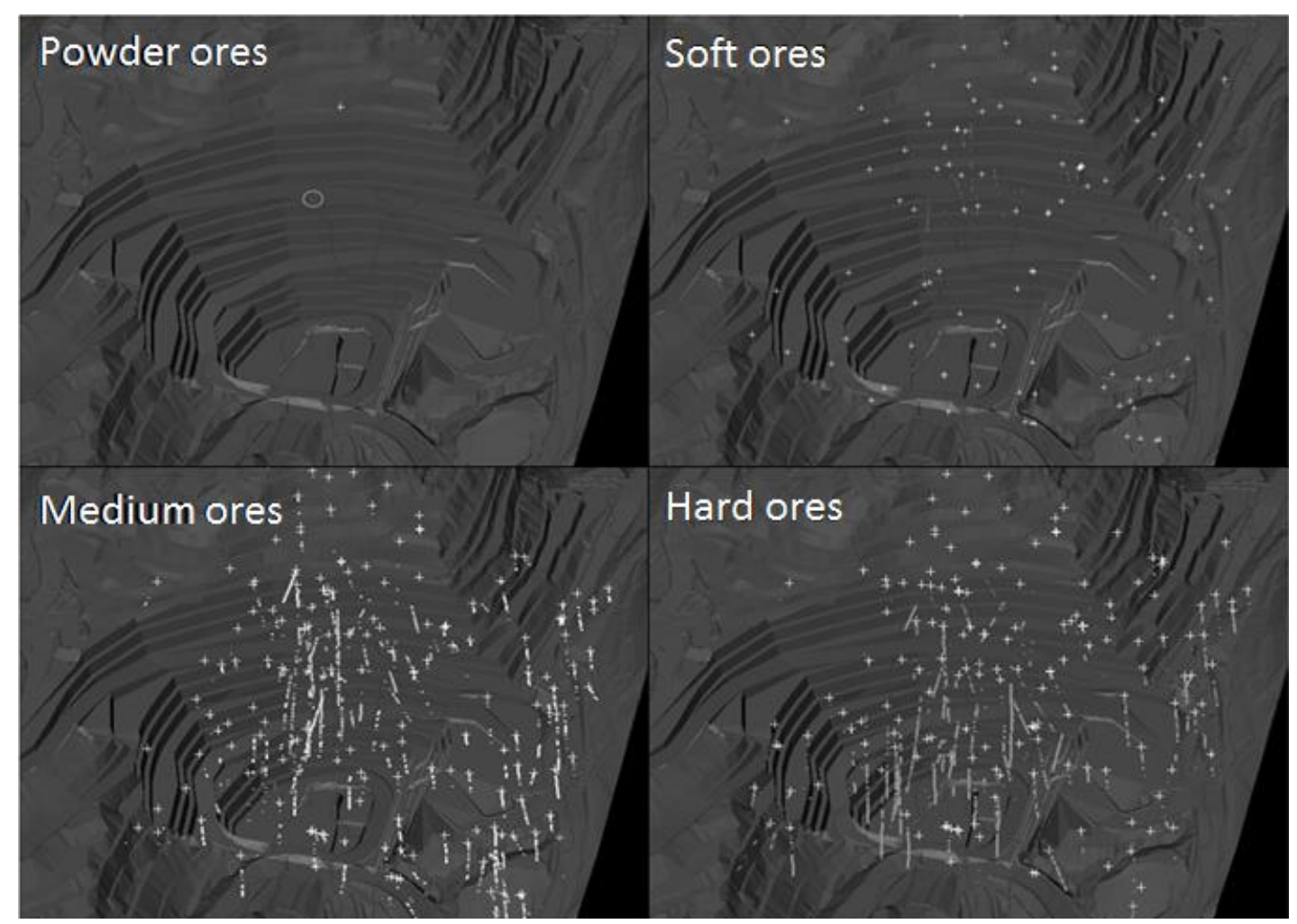

Figure 15 Borehole intercepts coloured by ore hardness codes

- Back-analysis of the preceding STR2 cut with Brazilian fines ore strengths using 2D limit equilibrium analysis. For the weakest ore strength, the STR2 slope FS fell below 1.0. This result is not supported by slope performance.

- The rock mass strength of the FLAC3D ${ }^{\mathrm{TM}}$ model was also downgraded to test the overall stability of STR3 with reduced ore strength and for comparison with STR2 performance. The model predicted failures with reduced strength that did not occur in reality, indicating that the reduced properties adopted for these sensitivity analyses were too conservative for STR2.

\subsection{Factor (disturbance depth)}

As discussed, blast damage was represented in the base case model by eliminating the cohesion from all ubiquitous joints within $20 \mathrm{~m}$ of the pit face. Additional models were run to investigate the sensitivity of the results to the depth of the simulated blast damage. This included a model with no blast damage, and a model with the depth of blast damage increased to $40 \mathrm{~m}$ behind the pit face.

The depth of simulated blast damage was found to have no significant impact on the modelling results. This is probably because the depth of blast damage is relatively shallow when compared to the overall scale of the slope, and in some areas, the bedding orientations are favourable, therefore reducing the bedding cohesion does not affect slope stability in these areas.

\subsection{Assignment of shale defect shear strength in 3DEC}

To illustrate the dominance of the shale bands on the behaviour of the rock mass, a series of triaxial tests were simulated in $3 \mathrm{DEC}^{\mathrm{TM}}$ for the footwall zone unit, with a reduced bedding shear strength. In this case, the strength of the non-shale bedding planes was reduced to the same properties as the shale bands. (Note that the non-shale bedding is typically assigned a higher shear strength than the shale bands). Figure 16 illustrates the anisotropic strength curve obtained from this analysis compared to the base case strength curve, where the strength of the non-shale bedding planes was significantly higher. The small difference between the two strength curves indicates that the strength of the non-shale bedding planes has only a 
minor influence on the behaviour of the rock mass. This is because the behaviour is mainly controlled by the shale bands, which are explicitly included in the 3DEC ${ }^{\mathrm{TM}}$ samples. This is not surprising, given that previous slope instability in the Pilbara is typically associated with the presence of relatively weak and persistent shale bands.

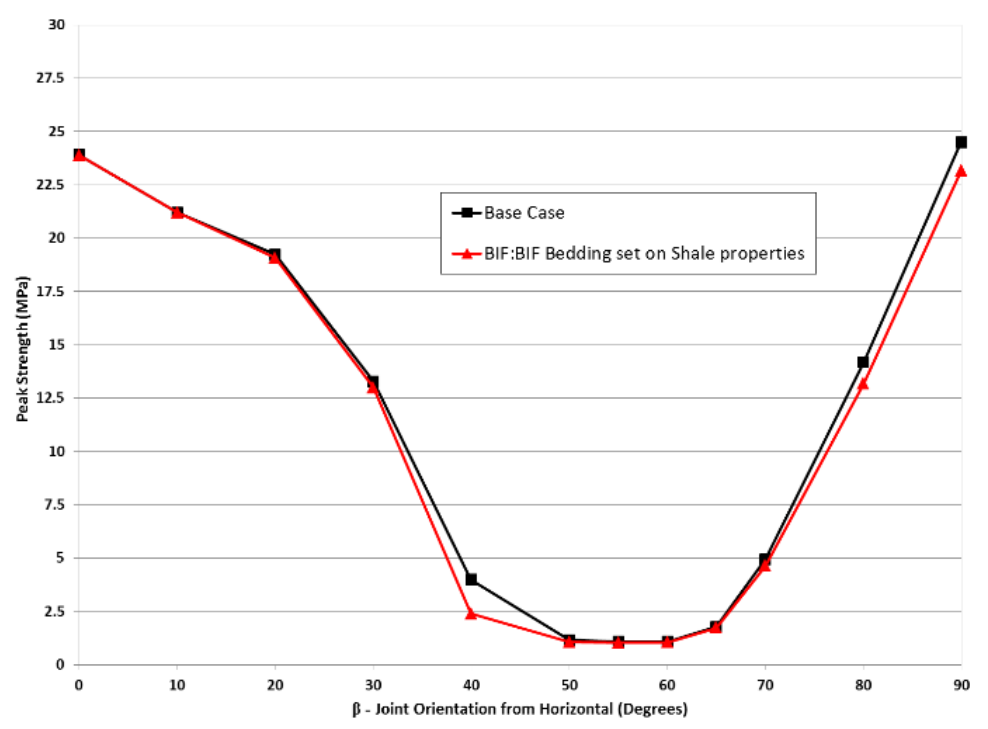

Figure $163 \mathrm{DEC}^{\mathrm{TM}}$ anisotropic strength in footwall zone unit with shale properties assigned to all bedding

\section{Batter assessment}

Optimisation design work discussed in Section 8.2 included steepening the batter face angle (BFA) to $90^{\circ}$. However, the implications for batter scale stability and rockfall protection needed to be evaluated.

For batter scale stability, a structural wedge mechanism was evaluated with Rocscience Dips ${ }^{\mathrm{TM}}$ (Rocscience 2015a) used to identify kinematically valid wedges. Rocscience Swedge ${ }^{\mathrm{TM}}$ was used to evaluate potential wedge shape, volume, interaction with the slope, and FS.

A total of 13 kinematically feasible wedges were identified in Dips and assessed in Swedge ${ }^{\mathrm{TM}}$ (Rocscience 2015b). More wedges were formed for $90^{\circ}$ BFA models than in the $80^{\circ}$ BFA and the wedges in all but one of these instances have joints as one of the release surfaces. These wedges are surficial and are expected to be removed during batter pulling. It was concluded that $20 \mathrm{~m}$ high batters with $90^{\circ}$ BFA and $10 \mathrm{~m}$ catch berms are suitable for use in the STR3 design and have a similar risk profile to the $80^{\circ}$ BFA configuration.

Simplified slope geometries were constructed in Rocscience rock fall modelling software RocFall ${ }^{\mathrm{TM}}$ (Rocscience 2015c) to assess berm catch performance for both $80^{\circ} \mathrm{BFA}$ and $90^{\circ} \mathrm{BFA}$. For geometries with $90^{\circ}$ BFA all rockfalls generated were contained on the catch berm regardless of batter height. It is considered critical that drill and blast activities are carried out with final wall finish in mind to minimise rock fall potential. Blast trials to demonstrate achievability of $90^{\circ}$ BFA in the various rock mass domains have been recommended. These should be carried out on production blast faces whilst the best blast design configuration is being developed.

\section{Conclusion}

As with all approaches when first used in a new environment, the method often requires more effort to implement than might be the case for subsequent applications. RTIO considers appointment of an independent review board to have been essential to help identify what model and geological assumptions should be tested during the process. Ultimately, application of a 3D modelling process is a fundamentally more realistic approach than previous $2 \mathrm{D}$ analysis methods. The base case model resulted in realisation of the initial 'protect plan' goal of the project (retention of the existing design). Further to this, an opportunity to optimise and add business value was identified. 
The optimised design presents a significant opportunity to realise steeper slope angles and defer additional waste stripping to maximise ore recovery. However, this will require co-commitments from various stakeholders in order to achieve this (i.e. careful limits blasting, excavation control and ongoing verification of design assumptions and objectives).

\section{References}

Aquino, TVC, Figueiredo, RP \& Franca, P 2009, 'Geological and geotechnical characterization and failure mechanism of Friable Hematitic Ore in Vale iron ore mines. West of Iron Ore Quadrangle, MG - Brazil', in Proceedings: Slope Stability 2009, Santiago de Chile, v. Único.

Barton, NR \& Bandis, S, 'Review of predictive capabilities of JRC-JCS model in engineering practice', in N Barton \& O Stephansson (eds), Rock joints, Proceedings of the International Symposium on Rock Joints, Loen, Norway, Balkema, Rotterdam, pp. 603-610.

Bitencourt, R, Mackenzie, P, Gordon, J \& Morey, B 2002, 'High-grade optimisation and improved grade control practices at Mount Tom Price', in Proceedings of the Iron Ore Conference, AUSIMM, Melbourne, pp. 261-277.

Cai, M, Kaiser PK, Tasaka, Y \& Minami, M 2007, 'Determination of residual strength parameters of jointed rock masses using the GSI system', International Journal of Rock Mechanics and Mining Sciences, vol. 44, pp. 247-265.

Dalstra, HJ 2014, 'Structural evolution of the Mount Wall region in the Hamersley province, Western Australia and its control on hydrothermal alteration and formation of high-grade iron deposits', Journal of Structural Geology, vol. 67, pp. $268-292$.

Hoek, E \& Karzulovic, A 2000, 'Rock mass properties for surface mines', in WA Hustrulid, MK McCarter \& DJA Van Zyl (eds), Slope Stability in Surface Mining, Littleton, Colorado, SME, pp. 59-70.

Hoek, E, Carranza-Torres, C \& Corkum, B 2002, 'Hoek-Brown Failure Criterion - 2002 edition', in R Hammah, W Bawden, J Curran \& M Telesnicki (eds), NARMS-TAC2002: Mining and Tunnelling Innovation and Opportunity, University of Toronto Press, Toronto, pp. 267-273.

Itasca 2012, FLAC $3 D$, Fast Lagrangian Analysis of Continua in 3 Dimensions, software, version 5.0, Itasca Consulting Group, Minneapolis. Itasca 2013a, 3DEC, Three-Dimensional Distinct Element Code, software, version 5.0, Itasca Consulting Group, Minneapolis.

Itasca 2013b, Kubrix Geo Automatic Grid Generator, software, version 12, Itasca Consulting Group, Minneapolis.

Maptek 2013, Vulcan ${ }^{T M}$, software, version 8.2.3, Maptek Pty Ltd, Adelaide.

Marinos, P \& Hoek, E 2001, 'Estimating the geotechnical properties of heterogeneous rock masses such as flysch', Bulletin of Engineering Geological Environments, vol. 60, no. 2, pp. 85-92.

Morris, RC 2002, 'Genesis of high-grade hematite orebodies of the Hamersley Province, Western Australia-A discussion', Economic Geology, vol. 97, pp. 177-181.

RITO (Rio Tinto Iron Ore) 2010, 'Geology and mineralogy of the Hamersley Province ores: Year 2010 update', unpublished internal report, Rio Tinto Iron Ore Pty Ltd.

Rocscience 2010, Slide Version 6.0 - 2D Limit Equilibrium Slope Stability Analysis, Rocscience Inc., Toronto, www.rocscience.com

Rocscience 2015a, Dips Version 6.0 - Graphical and Statistical Analysis of Orientation Data, Rocscience Inc., Toronto, www.rocscience.com

Rocscience 2015b, Swedge Version 6.0 - 3D Surface Wedge Analysis for Slopes, Rocscience Inc., Toronto, www.rocscience.com

Rocscience 2015c, RocFall Version 5.0 - Statistical Analysis of Rockfalls, Rocscience Inc., Toronto, www.rocscience.com

Sainsbury, DP \& Sainsbury, BL 2013, 'Three-dimensional Analysis of Pit Slope Stability in Anisotropic Rock Masses', in PM Dight (ed.) Proceedings of the International Symposium on Slope Stability in Open Pit Mining and Civil Engineering, Australian Centre for Geomechanics, Perth, pp. 683-696.

Stacey, PF 2009, 'Fundamentals of slope design', in J Read \& P Stacey (eds), Guidelines for Open Pit Slope Design, CSIRO Publishing, Collingwood, pp. 1-14.

Stacey, PF 2013, 'Review of Slope Design Studies for the STR3 Cut', unpublished letter report to RTIO, Stacey Mining Geotechnical Ltd.

Taylor, D, Dalstra, HJ, Harding, AE, Broadbent, G \& Barley, ME 2001, 'Genesis of high-grade hematite orebodies of the Hamersley Province, Western Australia', Economic Geology, vol. 96, pp. 837-873.

Tien, YM, Kuo, MC \& Juang, CH 2006, 'An experimental investigation of the failure mechanism of simulated transversely isotropic rocks', International Journal of Rock Mechanics and Mining Sciences, vol. 43, pp. 1163-1181.

Trendall, AF \& Blockley, JG 1970, 'The Iron Formations of the Precambrian Hamersley Group, Western Australia with Special reference to the associated Crocidolite', Bulletin 119, Geological Survey of Western Australia, Perth.

Tyler, IM 1991, 'The Geology of the Sylvania Inlier and Southeast Hamersley Basin', Bulletin 138, Geological Survey of Western Australia, Perth.

Villaescusa, E, Windsor, CR \& Machuca, L 2012, 'Stress measurements from oriented core - a decade of results', MassMin2012, Sudbury.

Wines, DR 2015, 'A Comparison of Slope Stability Analyses in Two and Three Dimensions', in Proceedings of Slope Stability 2015: International Symposium on Slope Stability in Open Pit Mining and Civil Engineering, SAIMM.

WSMP (World Stress Map Project) 2013, World Stress Map Project, http://dc-app3-14.gfz-potsdam.de/pub/introduction/ introduction_frame.html 
